\title{
Influence of grass lawns on the summer thermal environment and microclimate of heritage sites: a case study of Fuling mausoleum, China
}

\author{
Xiaoyu Wang* ${ }^{*}$, Peng Liu and Gongwen Xu
}

\begin{abstract}
The thermal environment and microclimate of heritage sites has been severely impacted by rapid urbanization. This study collected various meteorological measurement data as a reference for computational fluid dynamics (CFD) simulation settings. Then CFD was applied to simulate the impact of lawns on the thermal environment and microclimate of Fuling Mausoleum. We found that lawns and soil can cool the air through evaporation, and thus have a specific cooling effect on the bricked ground. Simulations with the lawns, the bricked ground temperature decreased by $1.56-17.54^{\circ} \mathrm{C}$ than that simulations without the lawns at $14: 00$, a decrease of $2.68 \%-24.20 \%$. Under normal circumstances, when the wind speed or relative humidity increased, the ground temperature dropped. Greenbelt vegetation can adjust the microclimate and human thermal comfort indicators. The consistency of the difference between the actual measurement and the CFD simulation results shows that CFD simulation can thus accurately reflect the internal temperature field distribution if the selection of simulation parameters is reasonable. Theoretical calculation and analysis, experimental measurement research, and modern computer simulation analysis methods applied together constitute a complete system for studying modern physical environmental problems and can provide reliable and economic results.
\end{abstract}

Keywords: Thermal environment, Microclimate, Fuling mausoleum, Heritage site, CFD simulation

\section{Introduction}

As a result of the rapid expansion of urban areas, heritage sites that were initially located in the suburbs or rural areas of many cities have gradually become important inner city areas. The phenomenon of urbanization has caused severe impacts and changes to the natural environment, and the environmental landscape is also deteriorating. The natural vegetation cover has been replaced by buildings and urban infrastructure, which results in the well-known urban heat island effect [1].

*Correspondence: 704216608@qq.com

School of Architecture \& Civil Engineering, Shenyang University of Technology, Shenyang 110870, China
Several adaptation measures have been put into practice for their potential to affect the urban microclimate, mainly to reduce high temperatures [2-6]. The greening and vegetation of urban areas are the most investigated adaptation approaches as they can reduce the surface temperature of the surrounding environment [3, $7,8]$. The ambient temperature can also be decreased by evaporation and transpiration of plants. The main methods to study the effectiveness of vegetation in mitigating the heat island effect are field measurements $[7,9,10]$, ground control experiments [11], and computational fluid dynamics (CFD) simulation [12-18]. Of these, CFD evaluates the effectiveness of vegetation coverage in detail on the outdoor urban microclimate, which is an economical and practical method of
Springer Open

(c) The Author(s) 2021. This article is licensed under a Creative Commons Attribution 4.0 International License, which permits use, sharing adaptation, distribution and reproduction in any medium or format, as long as you give appropriate credit to the original author(s) and the source, provide a link to the Creative Commons licence, and indicate if changes were made. The images or other third party material in this article are included in the article's Creative Commons licence, unless indicated otherwise in a credit line to the material. If material is not included in the article's Creative Commons licence and your intended use is not permitted by statutory regulation or exceeds the permitted use, you will need to obtain permission directly from the copyright holder. To view a copy of this licence, visit http://creativeco mmons.org/licenses/by/4.0/. The Creative Commons Public Domain Dedication waiver (http://creativecommons.org/publicdomain/ zero/1.0/) applies to the data made available in this article, unless otherwise stated in a credit line to the data. 
achieving accurate predictions. Hong and Lin [19] used the outdoor thermal simulation platform to discover the influence of the green layout on the outdoor environment and pedestrian thermal comfort. Bruce and Fleer [12] used CFD and ENVI-met models to simulate the microclimate and studied the impact of ground greening on the thermal stress coverage of small parks. Dimoudi and Nikolopoulou [13] used CFD model to compare the cooling effect of different methods and the vegetation arrangement in general building facilities. $\mathrm{Li}$ and $\mathrm{Yu}[20]$ used CFD to simulate the thermal environment and residential microclimate around a single building. They verified their simulation by comparing between the measured data with simulated temperature of the outdoor thermal environment around buildings. Bowler et al. [7] conducted an empirical study on the effect of urban greening for cooling effect. The main emphasis of previous research is on the evaluation of the indoor microclimate of heritage buildings and how to improve the comfort of users. Corgnati et al. [21] also described a methodology for evaluating the microclimate in museums between traditional convenience and thermal comfort. According to European standards such as EN 15,251 [22], La Gennusa et al. [23] analyzed the indoor climate and indoor environment in historical Italian buildings, including temperature and humidity.

CFD technology involves the solving of various conservation control partial differential equations describing fluid flow, heat transfer, and mass transfer and the visualization of the different solved flow or heat transfer phenomena. CFD technology, theoretical analysis and experimental research have become three essential fluid mechanics research methods. These three methods complement each other [24, 25]. To our knowledge, few studies focus on the outdoor thermal environment and microclimate for heritage sites. Because of urbanization around heritage sites, the summer temperatures are increasing. This study focused on the cooling effect of grassland and vegetation on the environment in summer. On the basis of actual measurement, the CFD simulation experiment was applied to analyze the cooling effect of the vegetation.

First, infrared images and precise measurements are taken with an infrared thermal imaging camera to collect various physical data in meteorology as a reference for CFD simulation settings. Then, CFD was used to simulate the impact of lawns on the thermal environment and microclimate of the heritage site. The research includes: (1) Analysis and comparison of the actual measurement with simulation results; (2) Analysis of the simulation results before and simulations with the lawns; (3) Analysis of the simulation results at different wind speeds and relative humidity; and (4) Analysis and comparison of the actual measurement of microclimate with the human thermal comfort index value.

\section{Methodology \\ Study site}

Shenyang is located in central Liaoning Province, southern northeast China $\left(41^{\circ} 12^{\prime} \mathrm{N}-43^{\circ} 02^{\prime} \mathrm{N}\right.$, $\left.122^{\circ} 25^{\prime} \mathrm{E}-123^{\circ} 48^{\prime} \mathrm{E}\right)$. Fuling Mausoleum is located in the eastern suburbs of Shenyang. It is the tomb of the Qing patriarch Nurhachi and his queen Yehenala and is one of the three mausoleums of Shengjing. Fuling Mausoleum was built in 1629 and was completed in 1651. After a great deal of construction works during the Shunzhi, Kangxi, and Qianlong periods of the Qing Dynasty, a large-scale and well-equipped ancient emperor tomb complex was formed. When it was first built, it was called "Xianhan Mausoleum" or "Taizu Mausoleum". In the first year of Chongde (1636), it was named "Fuling Mausoleum", which implies the long-lasting fortune of the Qing Dynasty [26]. In 2004, The Three Mausoleums of Shengjing (referring to Fuling, Zhaoling, and Yongling Mausoleums), were included on the UNESCO World Heritage Site List [27].

Fuling Mausoleum has a detailed layout and distinct levels and has a total area of approximately $194,800 \mathrm{~m}^{2}$. It is shaped like an inner city with an outer wall. It comprises three parts-the front yard, the square city and the treasure city-and it gradually increases in elevation from south to north. The mausoleum building complex remains relatively intact [28]. There are 32 existing ancient buildings, which are symmetrically distributed with the Shinto as the central axis. It is a complex of imperial tombs that integrates the characteristics of the Manchu and Han ethnicities, which differs from the tombs of the Ming Dynasty and those built after the Qing Dynasty [26]. This article focuses on the three main buildings of Fuling Mausoleum: Stele Pavilion, Long'en Gate and Long'en Hall (Fig. 1). The roads in front of the buildings are paved with bricks, and the grass lawns cover two sides of the bricked ground (Fig. 2).

\section{On-site measurements}

July is the hottest month of the year in Shenyang. The daily average temperature is between 28 and $29^{\circ} \mathrm{C}$, and the weather is usually in the range $24-32{ }^{\circ} \mathrm{C}$. The maximum ground temperature can reach $63{ }^{\circ} \mathrm{C}$. In July, the average wind speed is $3.64-3.86 \mathrm{~m} / \mathrm{s}$ and the wind direction is mainly southerly [29]. On July 12, 2020, when field measurements were taken at Fuling Mausoleum, the weather was clear and the wind speed was relatively low. To study the impact of lawns on the summer thermal environment and microclimate of Fuling Mausoleum, the 


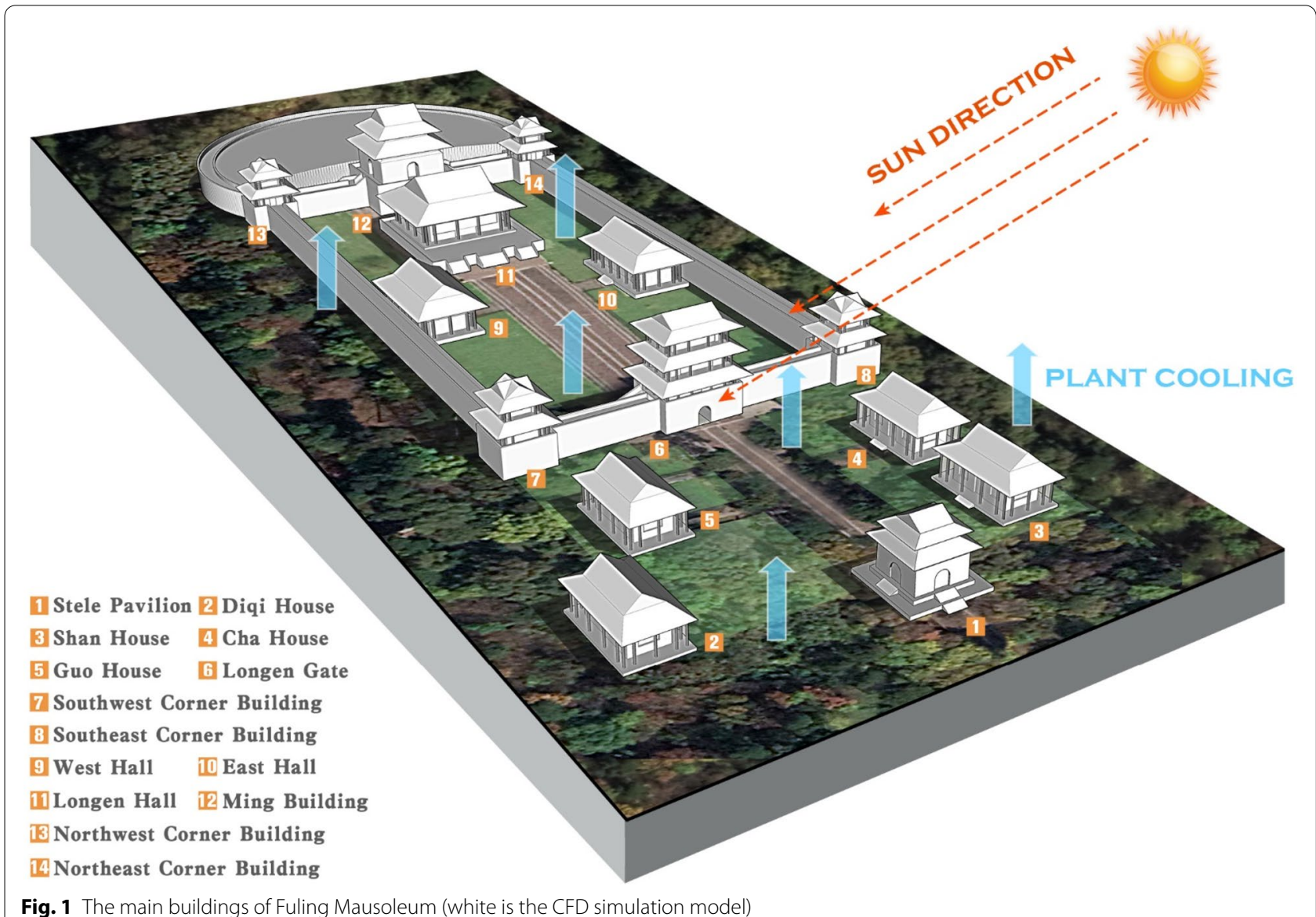

project team members selected five-time points -10:00, 11:00, 12:00, 13:00, and 14:00-and conducted the field measurements at these times. The measuring instruments (Table 1, Fig. 3) and measurement groups taken were as follows:

(1) Outdoor thermal environment. The primary measurement data were air temperature, black bulb temperature, relative humidity, wind speed, and the wet bulb globe temperature (WBGT) value. Measurement were taken $1.6 \mathrm{~m}$ from the ground in the open area in front of Long'en Gate to obtain biological data to describe the environment, and to measure the thermal environment and microclimate physical data of the surrounding lawns and the bricked ground.

(2) Infrared thermal imaging. The primary measurement contents were the real-time temperature of the lawns and the bricked ground. The measurement locations were selected in front of the Stele Pavilion, Long'en Gate, and Long'en Hall and included the bricked ground and lawns to the left and right of these structures. Infrared thermal imaging photos were taken to determine the realtime temperature at each measurement point.

(3) Surface heat flux measurement. The primary measurement contents were the heat flux data for the bricked ground and the green soil. The heat flow measurement points were placed on the floor of the bricked ground and at $10 \mathrm{~cm}$ soil depth in the lawns to measure the heat flux data of the different ground surfaces. The surface of the lawns was in an endothermic state and the measured heat flux was between -16.9 and $-16.8 \mathrm{~W} / \mathrm{m}^{2}$, whereas the bricked ground was in an exothermic state, and its heat flux was between 90.7 and $137.9 \mathrm{~W} / \mathrm{m}^{2}$ (Table 2).

\section{CFD approach}

Based on the actual measurement and theoretical research, the heat flux determined using ANSYS/Fluent was used to set two types of lawns and bricked ground to simulate the thermal environment and microclimate [30]. The heat flux of lawns and the bricked ground was measured as a reference. The grass material was found to 


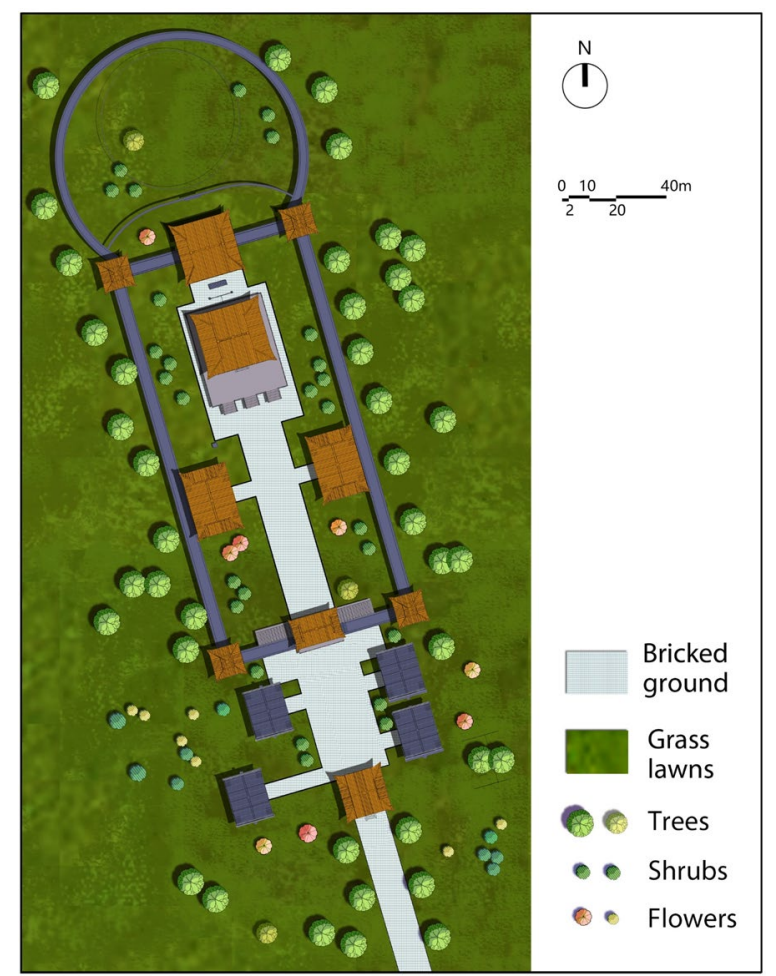

Fig. 2 The locations and dimensions of the bricked ground and grass lawns

absorb heat; thus the heat flux was set to a negative value for these areas. Conversely, the brick material emit heat, thus the heat flux was set to a positive value for these areas.

\section{Calculation area and boundary condition settings}

The calculation area was set to a rectangular parallelepiped area (1200 m long, $400 \mathrm{~m}$ wide, and $70 \mathrm{~m}$ high). The calculation area was mainly based on the ancient buildings from Stele Pavilion to Ming building and the surrounding environment. The southwest wind inlet was set to the velocity inlet of the simulation calculation range, the outlet was set to the pressure outlet, the boundary conditions of the ground and buildings were set to the wall, and the external calculation domain was set to the symmetry to assume actual atmospheric environmental conditions (Fig. 4).

\section{Mesh settings}

The mesh system setting was a numerical calculation method based on the finite volume method. The calculation area was divided into the appropriate mesh, and calculations were performed to determine the mass, momentum, and energy conditions in each mesh. In this study, the mesh was generated using ANSYS-ICEM software using tetrahedral elements in the fluid domain. The mesh contains between 2.39 million tetrahedral elements (Fig. 5).

In order to verify the mesh independence, the meshes were set to $1.04,1.08,1.53,2.39,3.52$ million tetrahedral elements. We took ten points on the ground in front of Long'en Hall to measure the temperature values. It could be seen from Fig. 5a that when the number of elements in mesh changed from 2.39 million to 3.52 million, the temperature value of ten points changed little with the increase of the number of elements. Refinement of the mesh (the addition of more elements) had little impact on the calculation results. It could be considered that 2.39 million elements in mesh had reached mesh independence.

\section{RNG $k-\varepsilon$ Model}

We used the RNG $k-\varepsilon$ model for viscous modeling. The RNG $k-\varepsilon$ model was proposed by Orszag and Yakhot [31]. Although similar in form to the standard $k-\varepsilon$ model, the RNG $k-\varepsilon$ model is more accurate and reliable for a wider class of flows [32]. The turbulence kinetic energy, and its rate of dissipation, $\varepsilon$, are obtained from the following transport equations [30]:

Table 1 Measuring instruments and measuring parameters

\begin{tabular}{|c|c|c|}
\hline Measuring instruments & Measuring parameters & Instrument accuracy \\
\hline \multirow{4}{*}{$\begin{array}{l}\text { Black bulb thermometer } \\
\text { Temperature and humidity tester } \\
\text { WBGT Tester }\end{array}$} & Air temperature & $\pm 0.1{ }^{\circ} \mathrm{C}$ \\
\hline & Black bulb temperature & $\pm 0.1{ }^{\circ} \mathrm{C}$ \\
\hline & WBGT Heat index & $\pm 0.1{ }^{\circ} \mathrm{C}$ \\
\hline & Relative humidity & $\pm 5 \% \mathrm{RH}$ \\
\hline Anemometer & Wind speed & $\pm 3 \%$ 或 $\pm 0.1 \mathrm{dgt}$ \\
\hline Infrared thermal imaging thermometer & Object temperature imaging & $\pm 2 \%$ 或 $\pm 2{ }^{\circ} \mathrm{C}$ \\
\hline Heat flux sensor & Soil heat flux density, Heat flux density of bricked ground & $\pm 1 \mathrm{~W} / \mathrm{m}^{2}$ \\
\hline
\end{tabular}



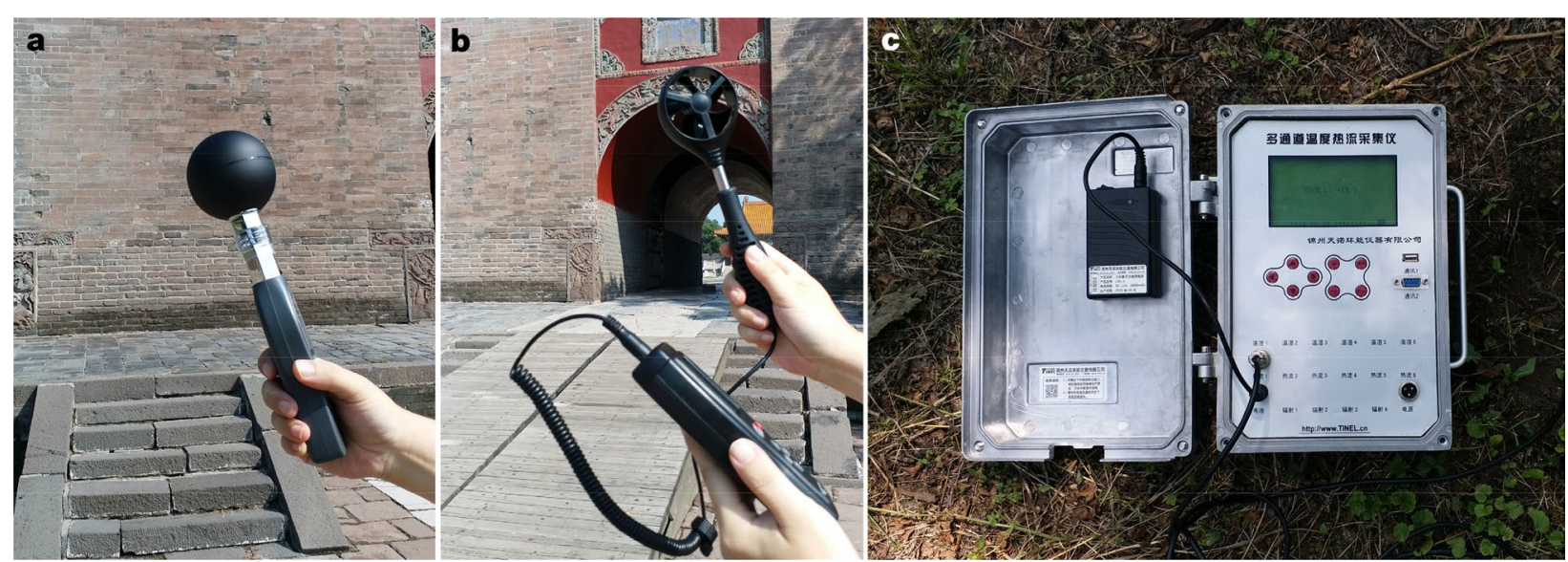

Fig. 3 Measuring instruments: a black bulb thermometer, b anemometer, c heat flux sensor (photos by Xiaoyu Wang)

Table 2 Actual measurement data

\begin{tabular}{llllll}
\hline $\begin{array}{l}\text { Time } \\
\text { (Hour) }\end{array}$ & $\begin{array}{l}\text { Air } \\
\text { temperature } \\
\left({ }^{\circ} \mathrm{C}\right)\end{array}$ & $\begin{array}{l}\text { Wind } \\
\text { speed } \\
(\mathbf{m} / \mathbf{s})\end{array}$ & $\begin{array}{l}\text { Relative } \\
\text { humidity(\%) }\end{array}$ & $\begin{array}{l}\text { Heat } \\
\text { flux } \\
\text { of grass } \\
\text { lawns } \\
\left(\mathbf{W} / \mathbf{m}^{\mathbf{2}}\right)\end{array}$ & $\begin{array}{l}\text { Heat flux } \\
\text { of bricked } \\
\text { ground } \\
\left(\mathbf{W} / \mathbf{~ m}^{\mathbf{2}}\right)\end{array}$ \\
\hline 10 & 26.1 & 3.6 & 68 & -16 & 90.7 \\
12 & 31.4 & 4 & 46.9 & -16.8 & 108.9 \\
14 & 33.7 & 5 & 40.1 & -16.8 & 137.9 \\
\hline
\end{tabular}

where $G_{k}$ and $G_{b}$ represent the turbulence kinetic energy generated from the mean velocity gradient and buoyancy, respectively; $Y_{M}$ represents the contribution of the fluctuating dilatation in compressible turbulence to the overall dissipation rate; $\alpha_{k}$ and $\alpha_{\varepsilon}$ denote the inverse effective Prandtl numbers for $k$ and $\varepsilon$, respectively; and $S_{k}$ and $S_{\varepsilon}$ are user-defined source terms.

\section{Wind profile}

Regarding the wind boundary layer over the terrain, the velocity profile specifying the inlet boundary condition for

$$
\frac{\partial}{\partial t}(\rho k)+\frac{\partial}{\partial x_{i}}\left(\rho k u_{i}\right)=\frac{\partial}{\partial x_{j}}\left(\alpha_{k} \mu_{e f f} \frac{\partial k}{\partial x_{j}}\right)+G_{k}+G_{b}-\rho \varepsilon-Y_{M}+S_{k}
$$

and

$$
\frac{\partial}{\partial t}(\rho \varepsilon)+\frac{\partial}{\partial x_{i}}\left(\rho \varepsilon u_{i}\right)=\frac{\partial}{\partial x_{j}}\left(\alpha_{\varepsilon} \mu_{e f f} \frac{\partial \varepsilon}{\partial x_{j}}\right)+C_{1 \varepsilon} \frac{\varepsilon}{k}\left(G_{k}+C_{3 \varepsilon} G_{b}\right)-C_{2 \varepsilon} \rho \frac{\varepsilon^{2}}{k}-R_{\varepsilon}+S_{\varepsilon}
$$

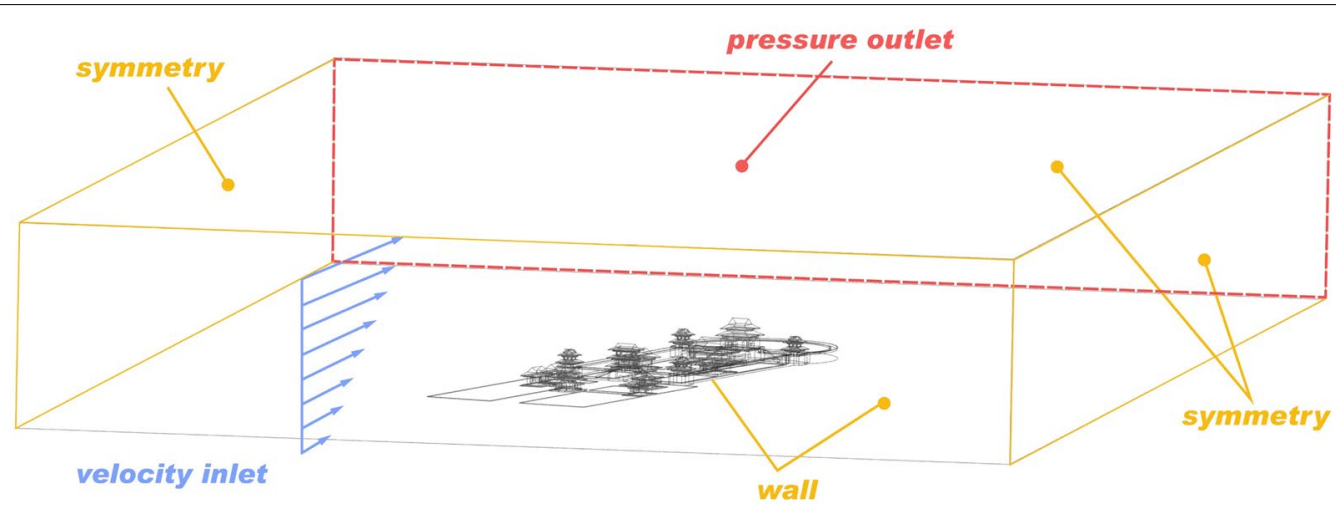

Fig. 4 General view of the computational domain (boundary condition settings) 

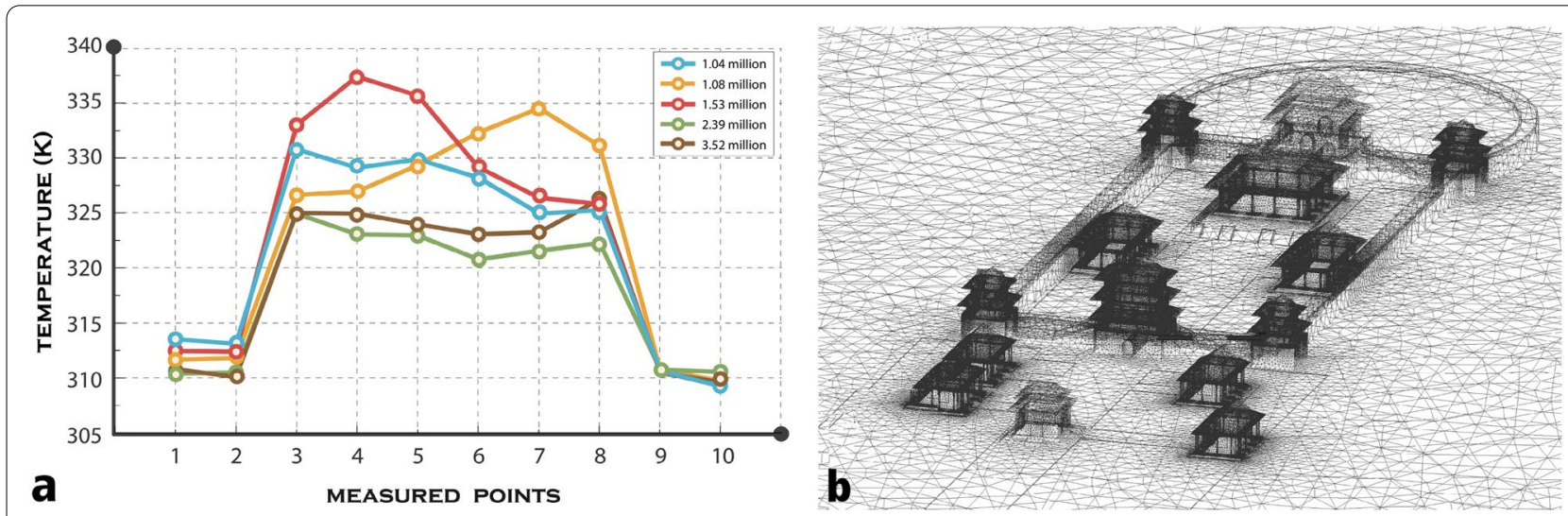

Fig. 5 a Mesh independence verification result. $\mathbf{b}$ Detail of the mesh refinement with tetrahedral elements

each simulation was defined according to this well-established equation [33],

$$
U_{z}=U_{10}\left(\frac{z}{10}\right)^{n_{p}}
$$

where $U_{z}$ denotes the air velocity which depends on height $\mathrm{z} ; U_{10}$ is the air velocity at the height of $10 \mathrm{~m}$ (assumed to be 4 or $10 \mathrm{~m} / \mathrm{s}$ ); and $n_{p}$ is the Hellman exponent, which depends on the atmospheric stability and the nature of the terrain. $n_{p}$ near the suburbs of the city is assumed to be 0.22 [33].

\section{Species transport equations}

When we choose to solve conservation equations for humidity, ANSYS Fluent predicts the local mass fraction of each species, $Y_{i}$, through the solution of a convectiondiffusion equation for the $i^{\text {th }}$ species. This conservation equation takes the following general form [30]:

$$
\frac{\partial}{\partial t}(\rho Y i)+\nabla \cdot(\rho \vec{v} Y i)=-\nabla \cdot \vec{J} i+R i+S i
$$

where $R_{i}$ is the net rate of production of species $i$ by chemical reaction and $S_{i}$ is the rate of creation by addition from the dispersed phase plus any user-defined sources. An equation of this form will be solved for $N-1$ species where $N$ is the total number of fluid phase chemical species present in the system. Since the mass fraction of the species must sum to unity, the $N$ th mass fraction is determined as one minus the sum of the $N-1$ solved mass fractions. To minimize numerical error, the $N$ th species should be selected as that species with the overall largest mass fraction.

\section{Settings of the numerical simulation scheme}

The real values collected according to actual measurement served as the basis for the verification of the numerical simulations. The impact of lawns and bricked ground on the thermal environment of ancient buildings was considered through the relative evaluation of the various physical values. The basic parameters of each material are shown in Table 3 [34]. The settings of the specific numerical simulation scheme are shown in Fig. 6.

\section{Results and discussion}

The heat exchange and distribution in the thermal environment of this site constitute a complex system, including various heat transfer processes such as convection, radiation, and heat conduction among mountains, rivers, air, and the earth. We focus on the influence of lawns on the summer thermal environment and microclimate of the architectural heritage site, which is mainly reflected in how wind speed, temperature, and humidity affect the cooling effect of vegetation.

\begin{tabular}{|c|c|c|c|c|c|}
\hline Material & Density $\left(\mathrm{kg} \mathrm{m}^{-3}\right)$ & $\begin{array}{l}\text { Specific heat capacity } \\
\left(\mathrm{J} \mathrm{kg}^{-1} \mathrm{k}^{-1}\right)\end{array}$ & $\begin{array}{l}\text { Thermal conductivity } \\
\left(\mathrm{W} \mathrm{m} \mathrm{m}^{-1} \mathrm{k}^{-1}\right)\end{array}$ & $\begin{array}{l}\text { Absorption } \\
\text { coefficient }\end{array}$ & $\begin{array}{l}\text { Refractive } \\
\text { coefficient }\end{array}$ \\
\hline Bricked ground & 2344 & 750 & 1.00 & 0.87 & 0.90 \\
\hline Wall & 1800 & 840 & 1.00 & 0.73 & 0.92 \\
\hline Lawns & 700 & 2310 & 1.20 & 0.00 & 0.20 \\
\hline
\end{tabular}

Table 3 Basic parameters of each material 


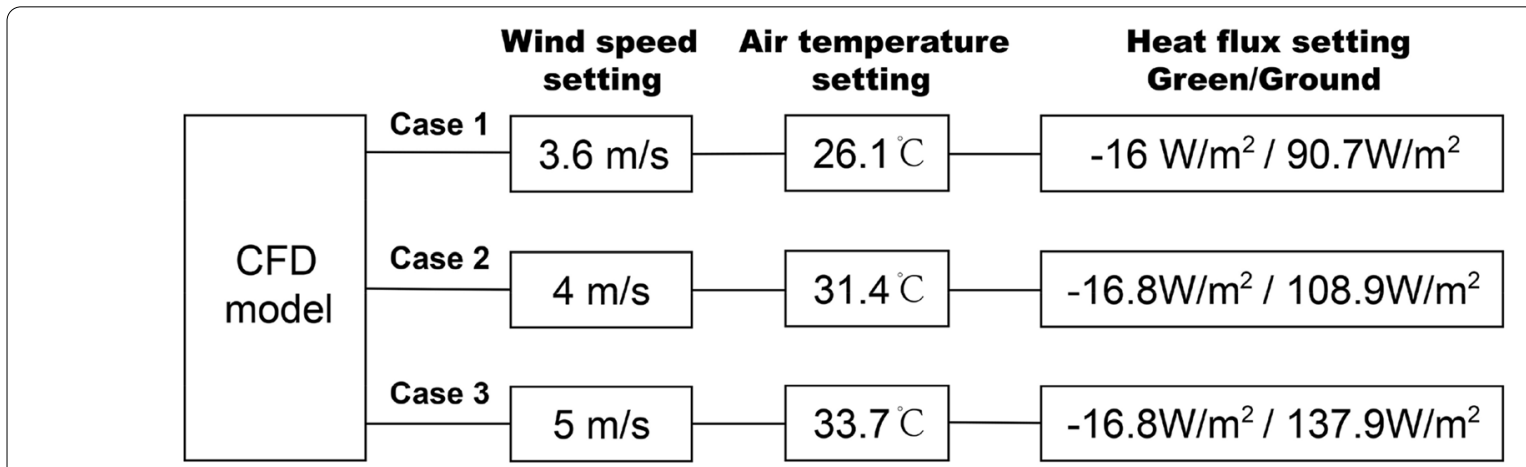

Fig. 6 Settings of the specific numerical simulation scheme

\section{Analysis of the actual measurement}

The project team took photos and infrared images of the bricked ground and lawns to the left and right in front of Stele Pavilion, Long'en Gate, and Long'en Hall at the fivetime points and obtained the data for each measuring point. To accommodate space limitations, we focused on the most explicit infrared image at 14:00 to study the role of local lawns on the thermal environment and microclimate regulation.

Figures 7, 8 and 9 present photos and infrared images of the bricked ground in front of Stele Pavilion, Long'en Gate, and Long'en Hall and lawns to the left and right of these sites taken at 14:00 using TESTO thermal imaging camera. The air temperature is affected by solar radiation

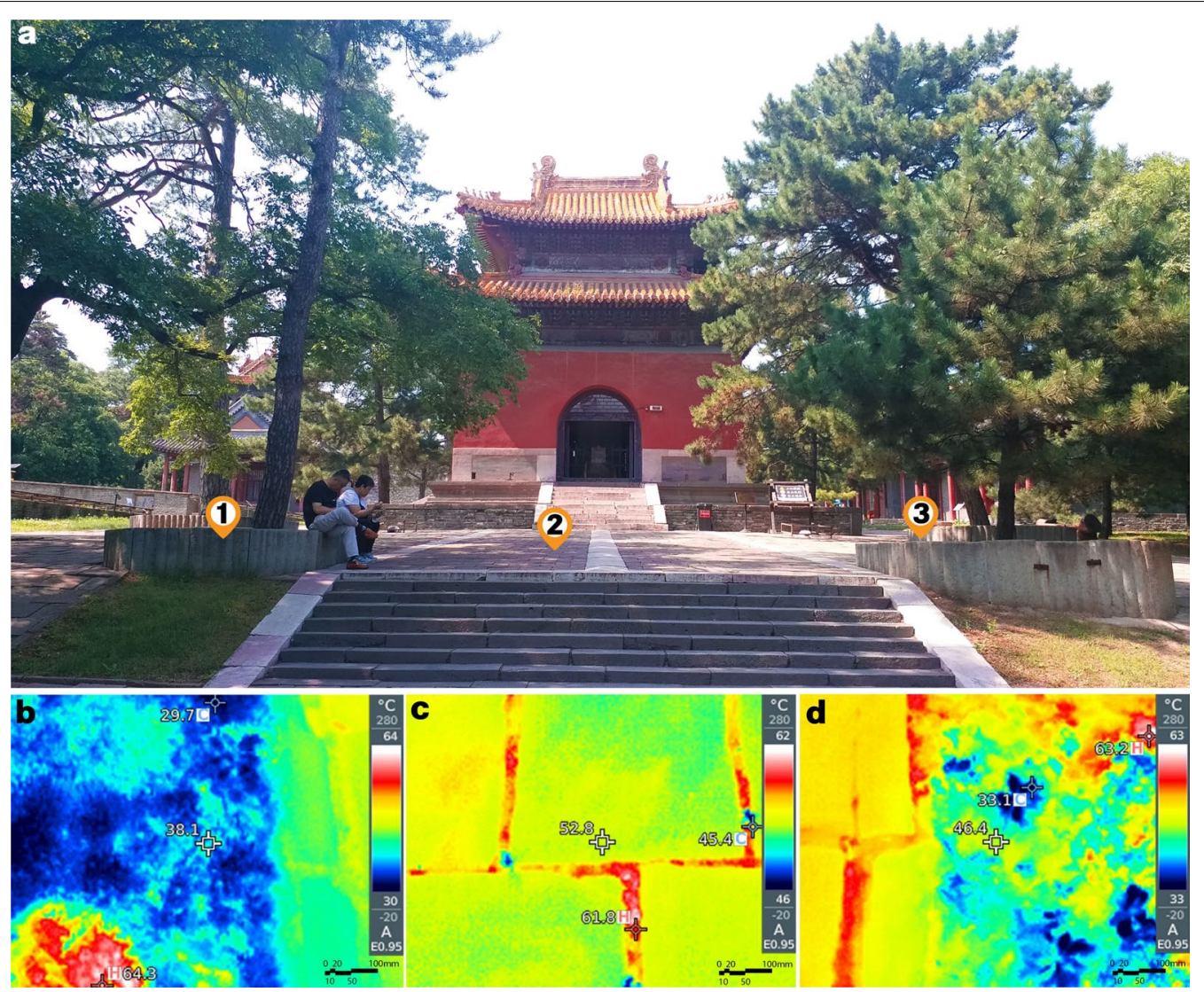

Fig. 7 Photo and infrared images of the site in front of Stele Pavilion: a photo of the site and overhead of $\mathbf{b}$ lawns to the left, $\mathbf{c}$ bricked ground, $\mathbf{d}$ lawns to the right 


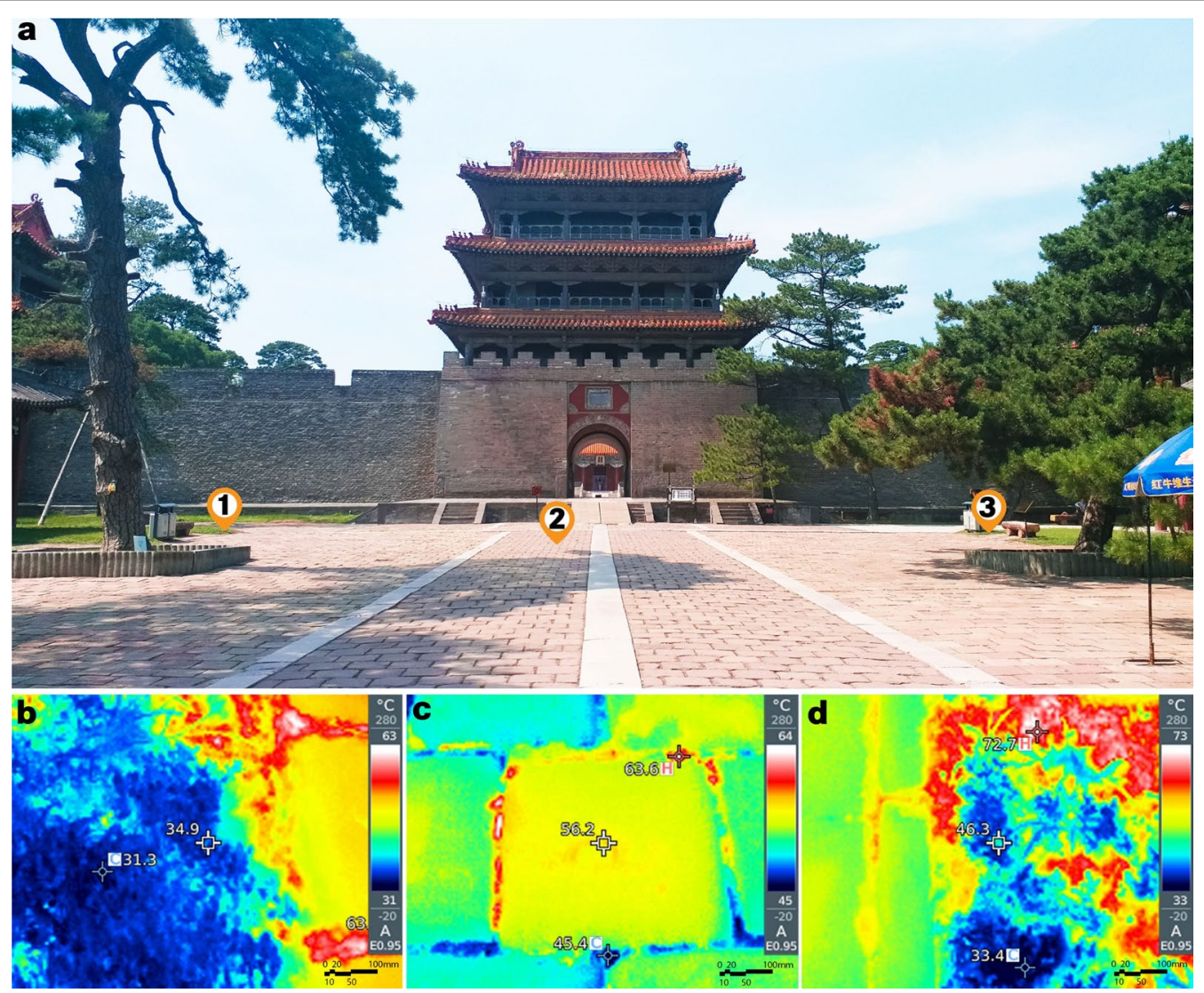

Fig. 8 Photo and infrared images of the site in front of Long'en Gate: a photo of the site and overhead of $\mathbf{b}$ lawns to the left, $\mathbf{c}$ bricked ground, $\mathbf{d}$ lawns to the right

and ground radiation. The air temperature peaked at around 14:00. After the ground absorbed solar radiation, the temperature also increased. The minimum temperature of green soil was still low, which indicates that the green soil could cool air through evaporation and cause a relatively low surface temperature. However, at the same time, the massive radiation absorption coefficient of the soil allowed it to absorb more heat radiation, which resulted in higher local heat production. As the temperature increased, the temperature change increased. The bricked ground did not have the evapotranspiration effect of green soil. The coefficient of absorbing radiation was small; therefore, the minimum and maximum temperature did not change as much as the soil of lawns. However, the greening of the surrounding environment affected on the bricked ground and had a specific cooling effect.

As shown in Figs. 7, 8 and 9, the lowest and highest temperatures of lawns to the left in front of Stele Pavilion were 29.7 and $64.3{ }^{\circ} \mathrm{C}$, respectively, those of lawns to the right were 33.1 and $63.2{ }^{\circ} \mathrm{C}$; and of the bricked ground were 45.4 and $61.8{ }^{\circ} \mathrm{C}$. The lowest and highest temperatures of lawns to the left in front of Long'en Gate were 31.3 and $63.0^{\circ} \mathrm{C}$, respectively, those of lawns to the right were 33.4 and $72.7^{\circ} \mathrm{C}$; and of the bricked ground were 45.4 and $63.6{ }^{\circ} \mathrm{C}$. The lowest and highest temperatures of lawns to the left in front of Long'en Hall were 39.8 and $59.7^{\circ} \mathrm{C}$, respectively, those of lawns to the right were 33.4 and $62.0{ }^{\circ} \mathrm{C}$; and of the bricked ground were 46.6 and $66.4^{\circ} \mathrm{C}$.

\section{Analysis and comparison of the actual measurement with simulation results}

The following relative error formula was used to assess the validity of the calculation results [35]:

$$
\delta=\frac{\Delta}{L} \times 100 \%
$$

where $\delta$ is the relative error between the measured value and the simulated value at a given time, $\Delta$ is the absolute error at that time (the absolute value of the difference between the measured value and the simulated value), and $L$ is the measured value at the time $\left({ }^{\circ} \mathrm{C}\right)$. 


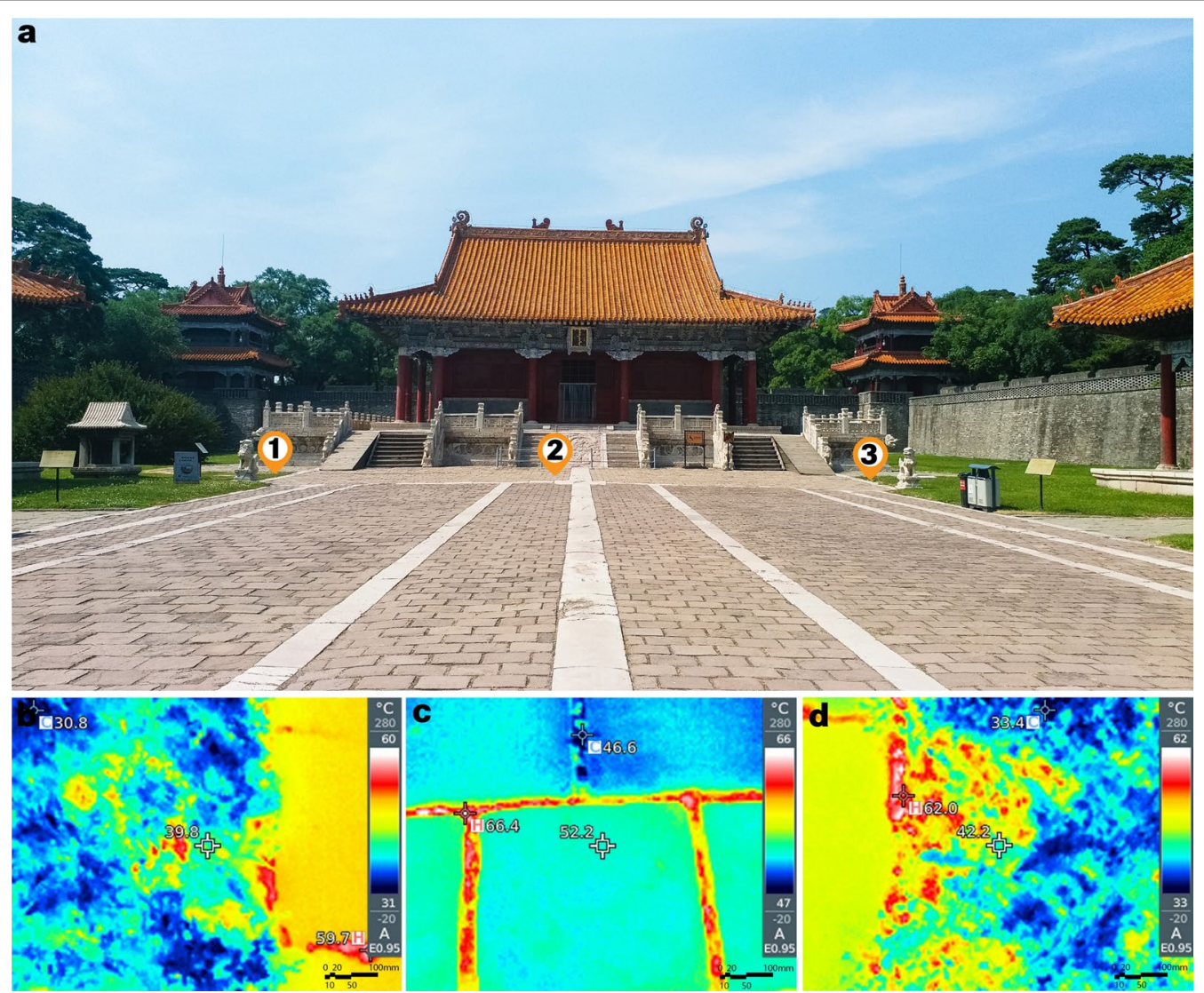

Fig. 9 Photo and infrared images of the site in front of Long'en Hall: $\mathbf{a}$ photo of the site and overhead of $\mathbf{b}$ lawns to the left, $\mathbf{c}$ bricked ground, $\mathbf{d}$ lawns to the right. (photo by Xiaoyu Wang)

Table 4 Relative error of the measured and simulated temperature values

\begin{tabular}{|c|c|c|c|c|}
\hline \multirow[t]{2}{*}{ Time (h) } & \multicolumn{4}{|c|}{ Relative error $\delta$ ratio in each interval (\%) } \\
\hline & $0 \% \leq \delta \leq 5 \%$ & $5 \%<\delta \leq 10 \%$ & $10 \%<\delta \leq 15 \%$ & $\delta>15 \%$ \\
\hline 10 & $26.7 \%$ & $33.3 \%$ & $33.3 \%$ & $6.7 \%$ \\
\hline 12 & $40 \%$ & $30 \%$ & $26.7 \%$ & $3.3 \%$ \\
\hline 14 & $53.3 \%$ & $36.7 \%$ & $6.7 \%$ & $3.3 \%$ \\
\hline
\end{tabular}

The error results of the measured and simulated temperature values of each measurement point on a typical day in each season are given in Table 4.

The consistency of the difference between the actual measurement and the CFD simulation results indicates that CFD could accurately reflect the internal temperature field distribution if the selection of simulation parameters was reasonable (Figs. 10, 11, 12). In particular, the difference between the actual measurement and the simulation was smallest at 14:00 and the simulated data were the closest to the actual measured data (see Table 4 and Fig. 10).

Figure 10a, b show the temperature cloud diagrams and the measurement point locations of the numerical simulation in front of Stele Pavilion, Long'en Gate, and Long'en Hall at 10:00. Figure 10c-e show the temperature comparison between the measured and simulated thermal environments in front of Stele Pavilion, Long'en Gate, and Long'en Hall at 10:00. Comparing the measured and simulated temperature curves, the difference between the measured and simulated values at 10 points was $0.15-7.16^{\circ} \mathrm{C}$ and the proportion was $0.51 \%-18.8 \%$. Figure $11 \mathrm{a}$, b show the temperature cloud diagrams and the measurement point locations of the numerical simulation in front of Stele Pavilion, Long'en Gate, and Long'en Hall at 12:00. Figure 11c-e show the temperature comparison between the measured and simulated thermal environments in front of Stele Pavilion, Long'en Gate, and Long'en Hall at 12:00. Comparing the measured and simulated temperature curves, the difference between the measured and simulated values at 10 points was $0.22-8.74{ }^{\circ} \mathrm{C}$ and the proportion was 

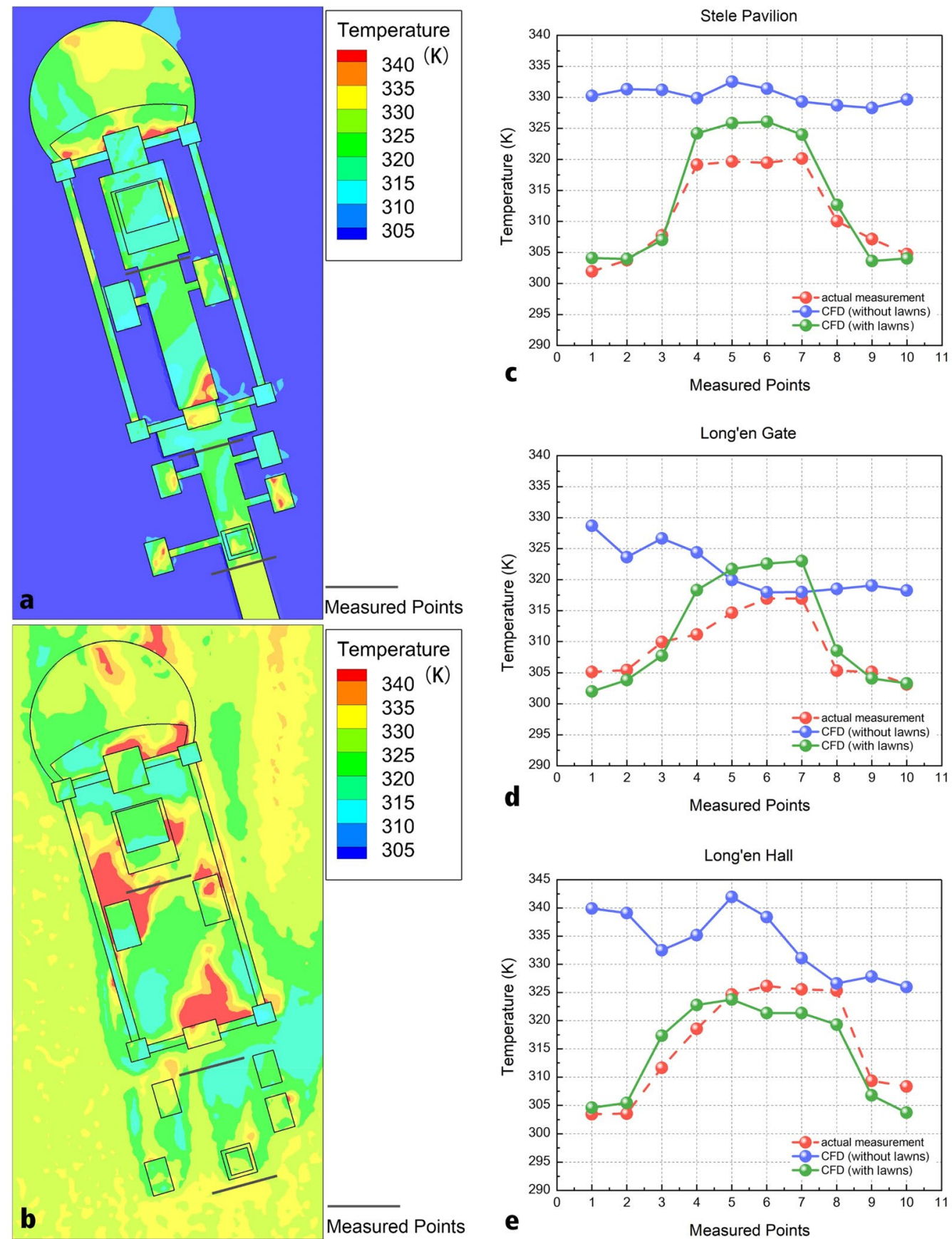

Fig. 10 Temperature cloud diagrams and measurement point locations of the numerical simulation at 10:00 a simulations with the lawns and b simulations without the lawns. Comparison of actual measurement with simulation results in front of Stele Pavilion at 10:00 c in front of Stele Pavilion, $\mathbf{d}$ in front of Long'en Gate, and $\mathbf{e}$ in front of Long'en Hall

$0.48-14.2 \%$. Figure 12a, b show the temperature cloud diagrams and the measurement point locations of the numerical simulation in front of Stele Pavilion, Long'en Gate, and Long'en Hall at 14:00. Figure 12c-e show the temperature comparison between the measured and simulated thermal environments in front of Stele Pavilion, Long'en Gate, and Long'en Hall at 14:00. Comparing the measured and simulated temperature curves, the difference between the measured and simulated values at 10 points was $0.02-7.55{ }^{\circ} \mathrm{C}$ and the proportion was $0.04-16.6 \%$. 

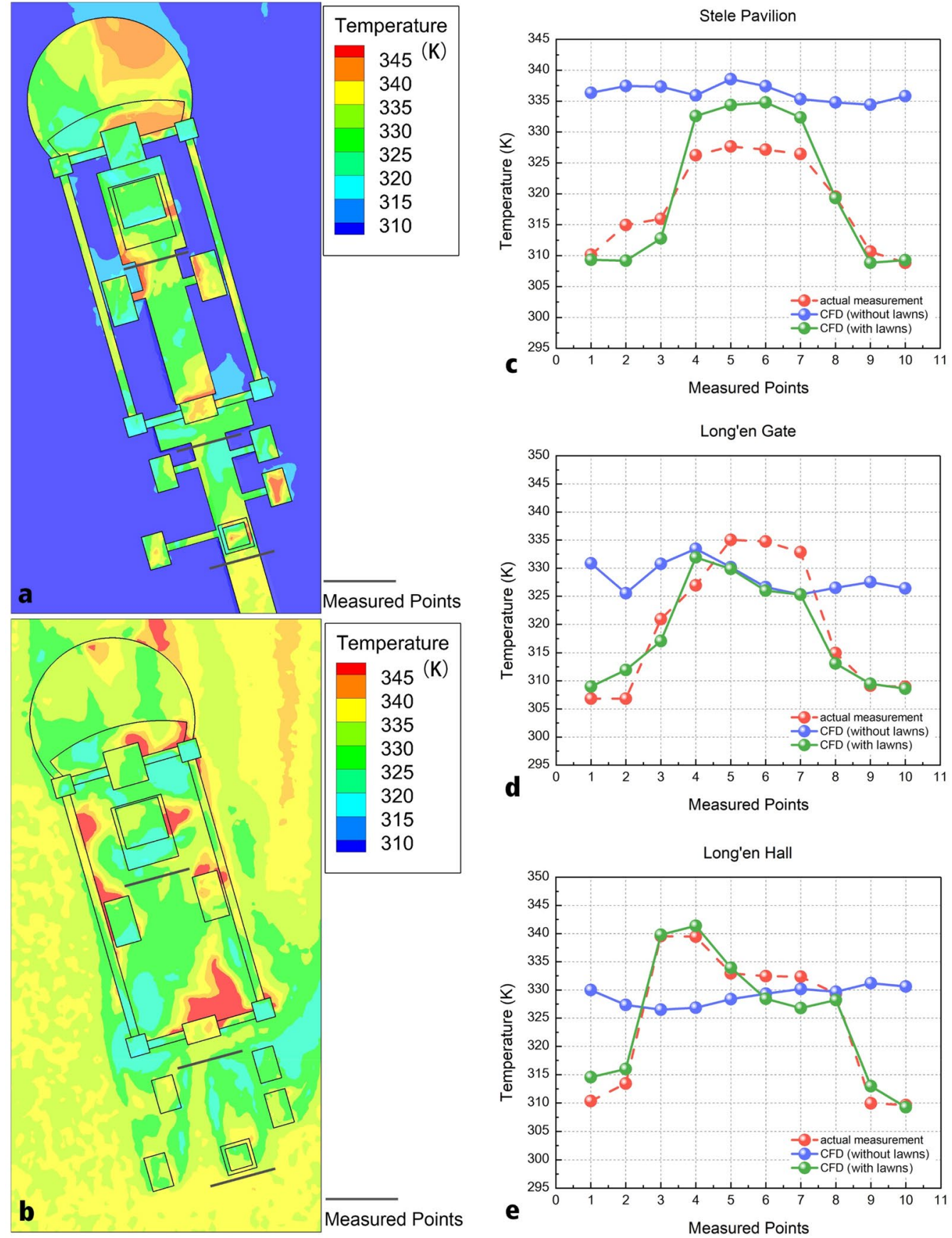

Fig. 11 Temperature cloud diagrams and measurement point locations of the numerical simulation at 12:00 a simulations with the lawns and b simulations without the lawns. Comparison of actual measurement with simulation results in front of Stele Pavilion at 12:00 c in front of Stele Pavilion, $\mathbf{d}$ in front of Long'en Gate, and $\mathbf{e}$ in front of Long'en Hall

\section{Analysis of the simulation results without and with the lawns}

Typically, simulations with the lawns, the temperature of the bricked ground in Fuling Mausoleum was lower than that simulations without the lawns at 10:00, 12:00 and 14:00.
Comparison of the simulated temperature curves without the lawns showed that the temperature of the bricked ground in front of Stele Pavilion at 10:00 decreased by $5.30-6.67{ }^{\circ} \mathrm{C}$ than that with the lawns, a decrease of $9.17 \%-11.24 \%$ (Fig. 10). The temperature of 

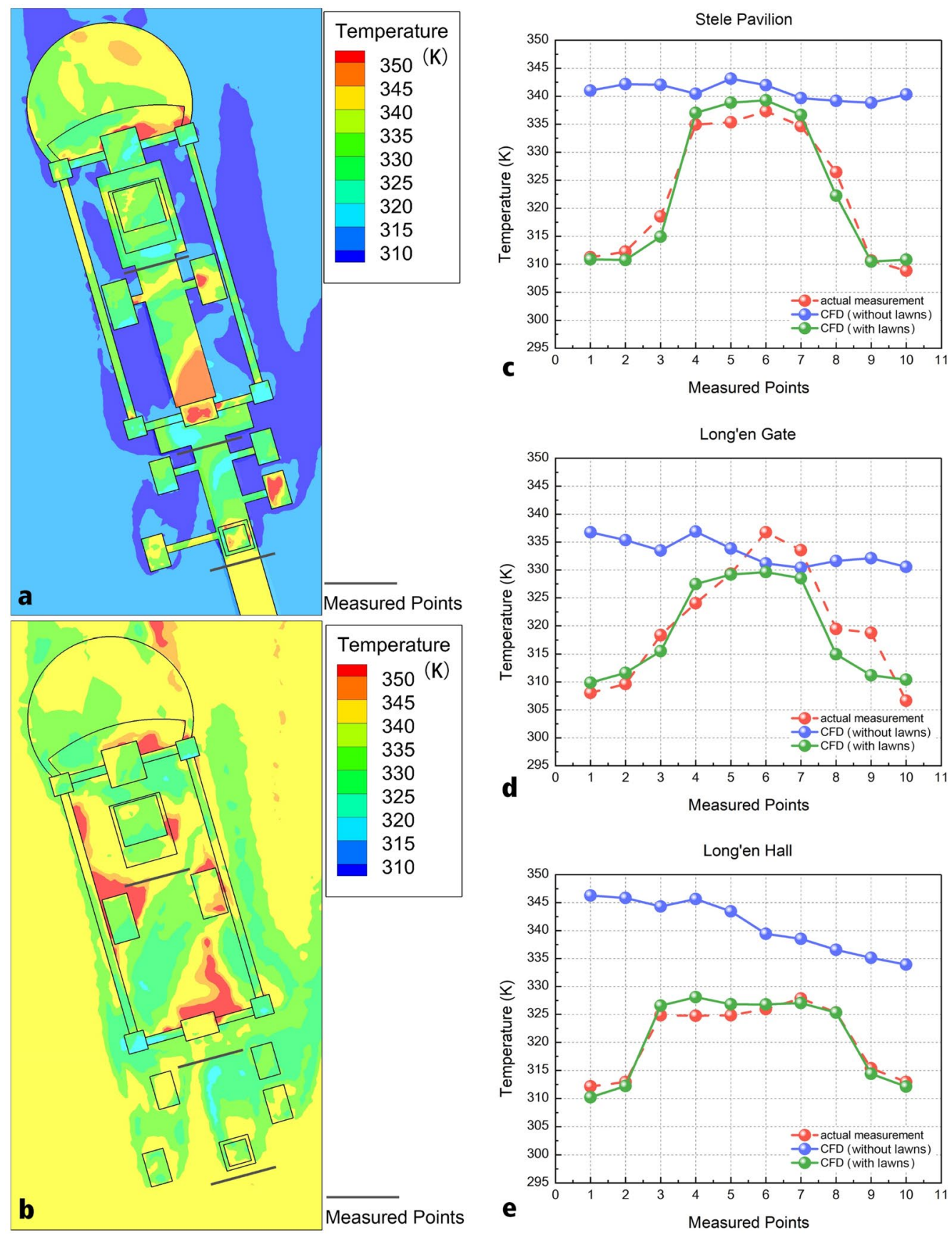

Fig. 12 Temperature cloud diagrams and measurement point locations of the numerical simulation at 14:00 a simulations with the lawns and b simulations without the lawns. Comparison of actual measurement with simulation results in front of Stele Pavilion at 14:00 c in front of Stele Pavilion, $\mathbf{d}$ in front of Long'en Gate, and $\mathbf{e}$ in front of Long'en Hall

the bricked ground in front of Long'en Gate decreased by $6.0{ }^{\circ} \mathrm{C}$, a decrease of $11.85 \%$. The bricked ground temperature in front of Long'en Hall decreased by 9.77-18.20 ${ }^{\circ} \mathrm{C}$, a decrease of $16.86 \%-26.45 \%$. Comparison of the simulated temperature curves without the lawns showed that the temperature of the bricked ground in front of Stele Pavilion at 12:00 decreased by $2.62-4.19{ }^{\circ} \mathrm{C}$ than that with the lawns, a decrease of $4.08 \%-6.40 \%$ (Fig. 11). The temperature of the bricked ground in front of Long'en Gate decreased by $0.02-1.55{ }^{\circ} \mathrm{C}$, a decrease of $0.04 \%-2.57 \%$. The bricked ground temperature in front of Long'en Hall decreased 
by $0.90-3.38{ }^{\circ} \mathrm{C}$, a decrease of $1.60 \%-5.93 \%$. Comparison of the simulated temperature curves without the lawns showed that the temperature of the bricked ground in front of Stele Pavilion at 14:00 decreased by $2.69-4.26{ }^{\circ} \mathrm{C}$ than that with the lawns, a decrease of $3.91 \%-6.09 \%$ (Fig. 12). The temperature of the bricked ground in front of Long'en Gate decreased by1.56$9.40{ }^{\circ} \mathrm{C}$, a decrease of $2.68 \%-14.75 \%$. The bricked ground temperature in front of Long'en Hall decreased by $11.47-17.54{ }^{\circ} \mathrm{C}$, a decrease of $17.56 \%-24.20 \%$. The temperature of some measured points had increased because of the effect of airflow vortexes. In air vortexes, the heat could not be taken away in time, which had increased the bricked ground temperature.

\section{Comparison and analysis of different wind speeds and relative humidity}

According to the comparison of actual measurement and simulation data, the difference between the actual measurement and the simulation at Fuling Mausoleum was smallest at 14:00 and the simulation data were the closest to the actual measurement data. In this study, the simulation parameters of wind speed and relative humidity at 14:00 were changed to study the influence of different results on the thermal environment and microclimate. Figure 13a-c present the wind speed cloud diagrams in the vertical direction of the central axis of Fuling Mausoleum at 10:00, 12:00, and 14:00. Figure 13d-f present the relative humidity cloud diagrams in the vertical direction of the central axis of Fuling Mausoleum at 10:00, 12:00, and 14:00.

Typically, as the wind speed increased, the ground temperature dropped. If the building was blocked by other walls, some of the measured points may be affected by airflow vortexes. Figure 13a-c show temperature comparison diagrams of Stele Pavilion, Long'en Gate, and Long'en Hall with different wind speed at 14:00. We found that simulations with the lawns, with a wind speed of $5 \mathrm{~m} / \mathrm{s} \mathrm{com-}$ pared with $4 \mathrm{~m} / \mathrm{s}$, the temperature of the bricked ground in front of Stele Pavilion decreased by $5.72-6.24{ }^{\circ} \mathrm{C}$, a decrease of $8.21 \%-8.67 \%$; the temperature of the bricked ground in front of Long'en Gate increased by $2.37-5.83{ }^{\circ} \mathrm{C}$, an increase of $4.03 \%-9.70 \%$; and the temperature of the bricked ground in front of Long'en Hall decreased by 14.17-19.27 ${ }^{\circ} \mathrm{C}$, a decrease of $20.50 \%-26.34 \%$. Compared with a wind speed of $5 \mathrm{~m} / \mathrm{s}$, at a wind speed of $6 \mathrm{~m} / \mathrm{s}$, the temperature of the bricked ground in front of Stele Pavilion
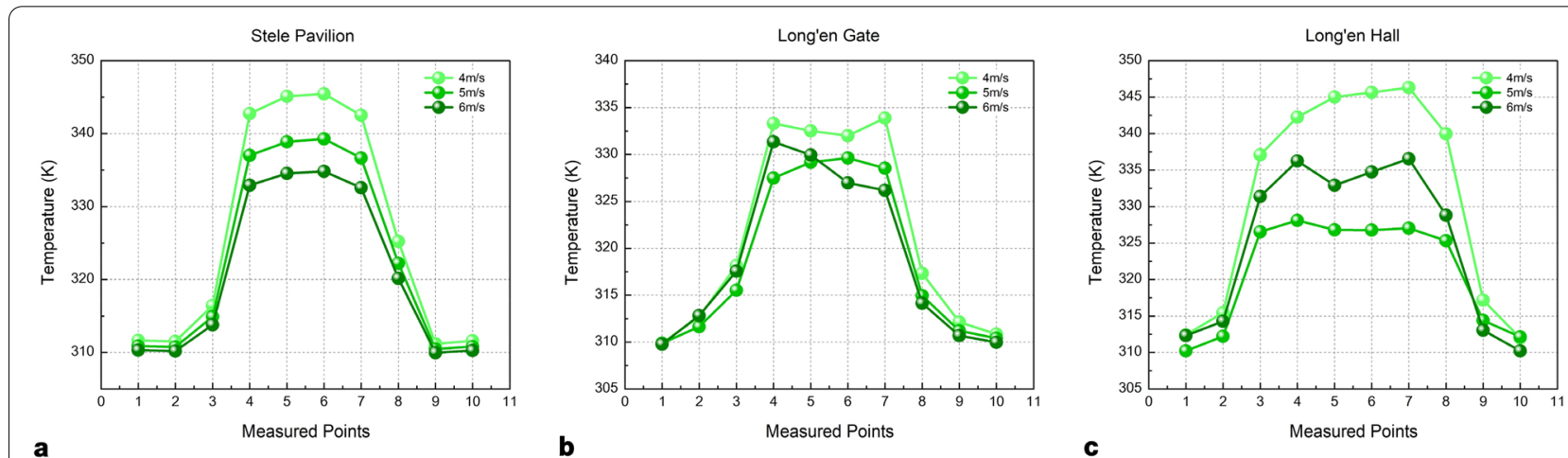

Fig. 13 Comparison of simulation results at different wind speeds at a Stele Pavilion, b Long'en Gate, and c Long'en Hall
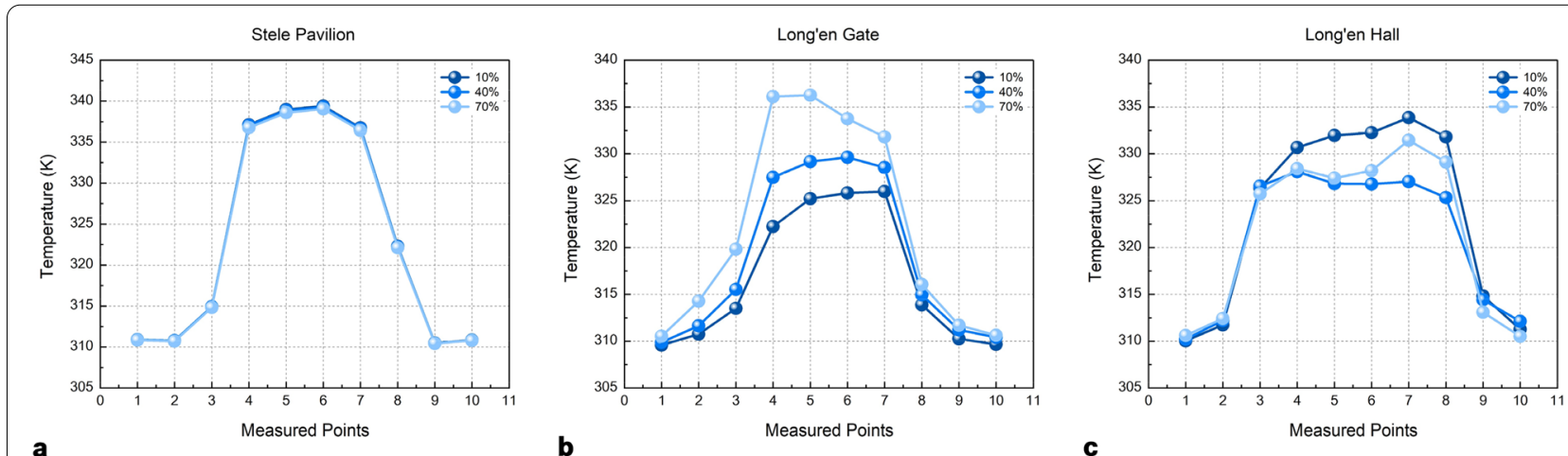

Fig. 14 Comparison of simulation results at different relative humidity at a Stele Pavilion, b Long'en Gate, and c Long'en Hall 


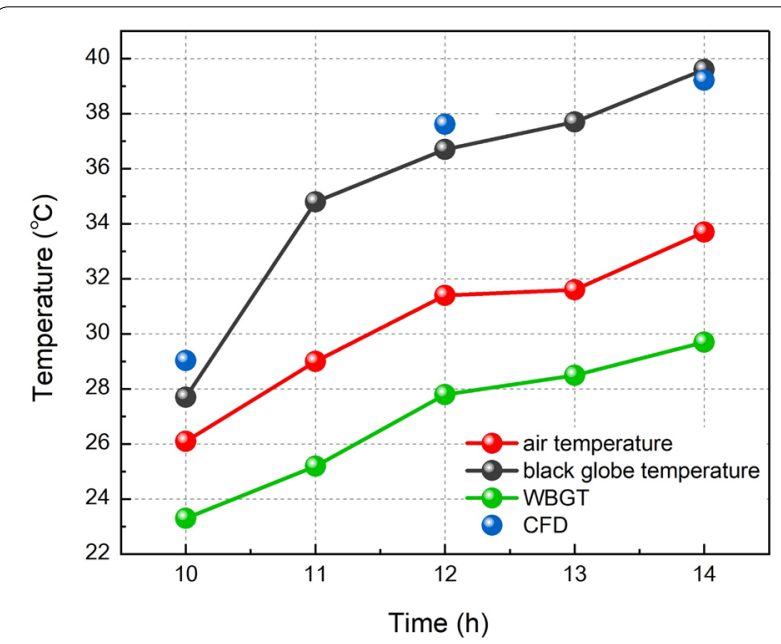

Fig. 15 Numerical simulation results were very close to the actual measurement data
Table 6 WBGT thermal comfort index [37]

\begin{tabular}{llllll}
\hline WBGT Index & Comfortable & Warm & Hot & Very hot & $\begin{array}{l}\text { Extremely } \\
\text { hot }\end{array}$ \\
\hline WBGT $\left({ }^{\circ} \mathrm{C}\right)$ & $<18$ & $18-24$ & $24-28$ & $28-30$ & $>30$ \\
\hline
\end{tabular}

Table 7 Real-time measurement of WBGT and black bulb temperature

\begin{tabular}{llll}
\hline $\begin{array}{l}\text { Time } \\
\text { (Hour) }\end{array}$ & $\begin{array}{l}\text { Air temperature } \\
\left({ }^{\circ} \mathrm{C}\right)\end{array}$ & $\begin{array}{l}\text { black bulb } \\
\text { temperature } \\
\left({ }^{\circ} \mathrm{C}\right)\end{array}$ & $\begin{array}{l}\text { WBGT } \\
\text { temperature } \\
\left({ }^{\circ} \mathrm{C}\right)\end{array}$ \\
\hline 10 & 26.1 & 27.7 & 23.3 \\
11 & 29 & 34.8 & 25.2 \\
12 & 31.4 & 36.7 & 27.8 \\
13 & 31.6 & 37.7 & 28.5 \\
14 & 33.7 & 39.6 & 29.7 \\
\hline
\end{tabular}

decreased by $4.06-4.44{ }^{\circ} \mathrm{C}$, a decrease of $6.39 \%-6.71 \%$; the bricked ground temperature in front of Long'en Gate decreased by $2.35-2.65^{\circ} \mathrm{C}$, a decrease of $4.24 \%-4.70 \%$; and the temperature of bricked ground in front of Long'en Hall increased by $6.10-9.53{ }^{\circ} \mathrm{C}$, an increase of $11.37 \%-17.69 \%$.

Similar to the relative humidity, as the relative humidity increased, the ground temperature dropped. If the building was blocked by other walls, the wind speed will decrease and the temperature of the ground will increase when the relative humidity increases. Figure $14 \mathrm{a}-\mathrm{c}$ show the temperature comparison diagrams of Stele Pavilion, Long'en Gate, and Long'en Hall with different relative humidity at 14:00. We found that compared with lawns planted at $10 \%$ relative humidity, simulations with the lawns at $40 \%$ relative humidity, the temperature of the tiled ground in front of Stele Pavilion decreased by 0.08 $0.11{ }^{\circ} \mathrm{C}$, a decrease of $0.12 \%-0.17 \%$; the temperature of the bricked ground in front of Long'en Gate increased by $2.55-5.25^{\circ} \mathrm{C}$, an increase of $4.83 \%-10.69 \%$; and the temperature of the bricked ground in front of Long'en Hall decreased by $2.57-6.82{ }^{\circ} \mathrm{C}$, a decrease of $4.47 \%-11.23 \%$. At $70 \%$ relative humidity instead of $40 \%$ relative humidity, the temperature of the bricked ground in front of Stele Pavilion decreased by $0.21-0.28{ }^{\circ} \mathrm{C}$, a decrease of $0.34 \%-0.43 \%$; the temperature of the bricked ground in front of Long'en Gate increased by $3.27-8.62{ }^{\circ} \mathrm{C}$, an increase of $5.91 \%-15.86 \%$; and the temperature of the bricked ground in front of Long'en Hall increased by $0.33-4.40^{\circ} \mathrm{C}$, an increase of $0.59 \%-8.17 \%$.

\section{Actual measurement of microclimate with the human thermal comfort index value}

Temperature is an important factor affecting human comfort and physical health. In the process of environment creation, it is essential that using vegetation to reduce air temperature and provide an excellent and suitable temperature environment for humans and the protection of architectural heritage [29]. At present, the most popular outdoor environmental evaluation indicators in China are the standard sufficient temperature and WBGT. The standard effective temperature index is used to evaluate the comfort of the environment (Table 5) [36] and the WBGT index is used to measure the safety of the thermal environment (Table 6) [37]. The project team members measured the air temperature, black bulb temperature, and WBGT values at five-time points (Table 7).

The human thermal comfort indexes in Tables 5 and 6 and the measured results in Table 7 show that at 10:00 as solar radiation illuminance increased, the air temperature gradually increased. At this time, the black bulb temperature value of the environment was $27.7^{\circ} \mathrm{C}$, between 25.6 and $30{ }^{\circ} \mathrm{C}$, and the WBGT index was $23.3{ }^{\circ} \mathrm{C}$, between 18 and $24{ }^{\circ} \mathrm{C}$, indicating a "warm" thermal sensation

Table 5 Standard effective temperature index [36]

\begin{tabular}{llllll}
\hline Thermal comfort index & Comfortable & Slightly warmer & Slightly hotter & Hot & Very hot \\
\hline Standard effective temperature $\left({ }^{\circ} \mathrm{C}\right)$ & $22.2-25.6$ & $25.6-30$ & $30-34.5$ & $34.5-37.5$ & $\geq 37.5$ \\
\hline
\end{tabular}


range. At 12:00, as a result of intense solar radiation, the ground accumulated a considerable amount of heat. The black bulb temperature measured was $36.7^{\circ} \mathrm{C}$ and WBGT measured was $27.8^{\circ} \mathrm{C}$. The thermal comfort index was in the "hot" thermal sensation zone. At 14:00, solar radiation was the strongest. The black bulb temperature measured was $39.6{ }^{\circ} \mathrm{C}$ and WBGT measured was $29.7{ }^{\circ} \mathrm{C}$. In these cases, the environment was "hot" or "very hot".

The main influences of outdoor environmental parameters on human thermal perception are temperature, humidity, solar radiation, and wind speed. Comparing the actual measurement with numerical simulation results, the thermal comfort of the investigation environment was calculated. The numerical simulation results were very close to the actual measurement data (Fig. 15).

\section{Conclusions}

The aims of this study were to compare measurement data and simulation results before and after planting grassland, compare the simulation results based on different wind speeds and relative humidity, and compare the actual measurements of the microclimate using the human thermal comfort index value, to reduce the damage to heritage sites caused by the heat island effect. The results of this research can be applied to the thermal environment and thermal comfort research of other heritage sites. The following conclusions were drawn from this study.

1. Because lawns and soil can cool the air through evaporation and the soil has a significant radiation absorption coefficient, it can also absorb more heat radiation and generate higher temperatures locally. The greening of the surrounding environment can affect the bricked ground and lead to a specific cooling effect.

2. The consistency of the difference between the actual measurement and the CFD simulation results indicates that the selection of simulation parameters was reasonable and could accurately reflect the internal temperature field distribution at Fuling Mausoleum. The CFD simulation was able to predict the temperature of the surrounding environment at heritage sites.

3. The simulated temperature of the bricked ground with the lawns was lower than that without the lawns. As the wind speed and relative humidity increased, the ground temperature dropped. If the building was blocked by other walls, the temperature of some measured points may be affected by airflow vortexes and the temperature of the bricked ground will increase when the wind speed increases.
4. The main influences of outdoor environmental parameters on human thermal perception are temperature, humidity, solar radiation, and wind speed. The actual measurement data were very close to the numerical simulation results.

We hope that our research is beneficial to propose the prevention and reinforcement measures timely and correspondingly to protect heritage buildings. There are some limitations of this study, for example, the measurements were taken only on a single day at a limited number of locations. A lot of actual physical measurements before and after planting lawns around historic buildings will be taken in a future research.

\section{Abbreviations}

CFD: Computational fluid dynamics; WBGT: Wet bulb globe temperature.

\section{Acknowledgements}

Not applicable.

Authors' contributions

$X Y-W$ has compiled the papers and produced the final manuscript, PL and GW-X have contributed to interpretation and written several sections. All authors read and approved the final manuscript.

\section{Funding}

This work was supported by the National Natural Science Foundation of China (Project No: 51978417), Natural Science Foundation of Liaoning Province (Project No: 2019-ZD-0207), Scientific Research Project of the Educational Department of Liaoning Province (Project No: LJGD2019012) and the Education and Teaching Reform Project of Shenyang University of Technology, China.

\section{Availability of data and materials}

The data is available within the article.

Ethics approval and consent to participate Not applicable.

\section{Consent for publication}

Written informed consent for publication was obtained from all participants.

\section{Competing interests}

The authors declare that they have no competing interests.

Received: 9 October 2020 Accepted: 23 December 2020

Published online: 13 January 2021

\section{References}

1. Ng E, Chen L, Wang Y, Yuan C. A study on the cooling effects of greening in a high-density city: an experience from Hong Kong. Build Environ. 2012;47:256-71. https://doi.org/10.1016/j.buildenv.2011.07.014.

2. Davies M, Steadman P, Oreszczyn T. Strategies for the modification of the urban climate and the consequent impact on building energy use. Energy Policy. 2008;36(12):4548-51. https://doi.org/10.1016/j.enpol 2008.09.013.

3. Gago EJ, Roldan J, Pacheco-Torres R, Ordóñez J. The city and urban heat islands: a review of strategies to mitigate adverse effects. Renew Sustain Energy Rev. 2013;25:749-58. https://doi.org/10.1016/j.rser.2013.05.057.

4. Christopher BF, Vicente RB, Michael DM. Climate Change 2014 Impacts, Adaptation, and Vulnerability Part A: Global and Sectoral Aspects. 
Working Group II Contribution to the IPCC 5th Assessment Report-Technical Summary; 2014.

5. Rizwan AM, Dennis YCL, Liu C. A review on the generation, determination and mitigation of urban heat island. Environ Sci. 2008;20(1):120-8. https ://doi.org/10.1016/S1001-0742(08)60019-4.

6. Rosenfeld AH, Akbari H, Bretz SE, Fishman BL, Kurn DM, Sailor DJ, Taha H. Mitigation of urban heat islands: materials, utility programs, updates. Energy Build. 1995;22:255-65. https://doi.org/10.1016/03787788(95)00927-P.

7. Bowler DE, Buyung-Ali L, Knight TM, Pullin AS. Urban greening to cool towns and cities: a systematic review of the empirical evidence. Landsc Urban Plan. 2010;97(3):147-55. https://doi.org/10.1016/j.landurbpla n.2010.05.006

8. Gill S, Handley J, Ennos AR, Pauleit S. Adapting cities for climate change: the role of the green infrastructure. Build Environ. 2007;33:115-33.

9. Chan ALS. Developing a modified typical meteorological year weather file for Hong Kong taking into account the urban heat island effect. Build Environ. 2011;46(12):2434-41. https://doi.org/10.1016/j.build env.2011.04.038.

10. Feyisa GL, Dons K, Meilby H. Efficiency of parks in mitigating urban heat island effect: an example from Addis Ababa. Landscape Urb Plann. 2014;123:87-95. https://doi.org/10.1016/j.landurbplan.2013.12.008.

11. Park M, Hagishima A, Tanimoto J, Narita Kl. Effect of urban vegetation on outdoor thermal environment: field measurement at a scale model site. Build Environ. 2012;56:38-46. https://doi.org/10.1016/j.build env.2012.02.015.

12. Bruse $M$, Fleer $\mathrm{H}$. Simulating surface-plant-air interactions inside urban environments with a three dimensional numerical model. Environ Model Softw. 1998;13:373-84. https://doi.org/10.1016/S1364-8152(98)00042-5.

13. Dimoudi A, Nikolopoulou M. Vegetation in the urban environment: microclimatic analysis and benefits. Energy Build. 2003;35(1):69-76. https ://doi.org/10.1016/50378-7788(02)00081-6.

14. Fröhlich D, Matzarakis A. Modeling of changes in thermal bioclimate: examples based on urban spaces in Freiburg. Germany Theor Appl Climatol. 2013;111(3-4):547-58. https://doi.org/10.1007/s00704-012-0678-y.

15. Srivanit M, Hokao K. Evaluating the cooling effects of greening for improving the outdoor thermal environment at an institutional campus in the summer. Build Environ. 2013;66:158-72. https://doi.org/10.1016/j. buildenv.2013.04.012.

16. Vidrih B, Medved S. Multiparametric model of urban park cooling island. Urb Forest Urb Greening. 2013;12(2):220-9. https://doi.org/10.1016/j. ufug.2013.01.002.

17. Wen CY, Juan YH, Yang AS. Enhancement of city breathability with half open spaces in ideal urban street canyons. Build Environ. 2017;112:32236. https://doi.org/10.1016/j.buildenv.2016.11.048.

18. Yang AS, Juan YH, Wen CY, Su YM, Wu YC. Investigation on wind environments of surrounding open spaces around a public building. J Mech. 2016;33(1):101-13. https://doi.org/10.1017/jmech.2016.47.

19. Hong B, Lin BR. Numerical studies of the outdoor wind environment and thermal comfort at pedestrian level in housing blocks with different building layout patterns and trees arrangement. Renew Energy. 2018;126:583-583. https://doi.org/10.1016/j.renene.2018.03.054.

20. Li XT, Yu Z. Numerical analysis of outdoor thermal environment around buildings. Build Environ. 2005;40(6):853-66. https://doi.org/10.1016/j. buildenv.2004.08.022
21. Corgnati SP, Fabi V, Filippi M. A methodology for microclimatic evaluation in museum: application to a temporary exhibit. Build Environ. 2009;44(6):1253-60. https://doi.org/10.1016/j.buildenv.2008.09.012.

22. EN15251. Indoor environmental input parameters for design and assessment of energy performance of buildings addressing indoor air quality, thermalenvironment, lighting and acoustics. Brussels: European Committee for Standarisation; 2008.

23. La Gennusa N, Lascari G, Rizzo G, Scaccianoce G. Conflicting needs of thethermal indoor environment of museums: in search of a practical com-promise. J Cult Herit. 2008;9(2):125-34. https://doi.org/10.1016/j. culher.2007.08.003

24. Shuzo. CFD and building environment design. Beijing: China Architecture Publishing; 2007

25. Yuan J, Liu JP. Numerical Simulation of Urban Street Valley Thermal Environment and Planning and Design Counter measures. Architecture Journal. 2007:3:37-9.

26. Wang $X Y$. Research on the overall protection model of the architectural cultural heritage area of the Qing Dynasty in Liaoning. Beijing: Science Press; 2016.

27. Wang YC. Fuling mausoleum in Shengjing (Qing Culture Series). Shenyang: Shenyang press; 2004

28. Liang Y. The Cultural Value of the Three Tombs in Shengjing. Vicissitudes. 2010;4:145-7.

29. China Meteorological Information centre. Special meteorological data set for China's building thermal environment analysis. Beijing: China Architecture Publishing; 2007

30. ANSYS FLUENT 16.0 Theory Guide. ANSYS, Inc. http://www.ansys.com

31. Orszag $S A$, Yakhot $V$. Renormalization group analysis of turbulence. In: Proceedings of the International Congress of Mathematicians, Berkeley; 1986:1395-1399

32. Orszag SA, Yakhot V, Flannery WS, Boysan F, Choudhury D, Maruzewski Patel B. Renormalization Group Modeling and Turbulence Simulations. In: International Conference on Near-Wall Turbulent Flows; 1993.

33. Hanna SR, Briggs GA, Hosker RP Jr. Handbook on atmospheric diffusion. United States: Technical Information Center U.S. Department of Energy; 1982.

34. Editorial department of Architectural Design Information Collection. Architectural Design Information Collection (Second Edition). Beijing: China Architecture Publishing; 1994.

35. Sheng JS, Zhang W, Gao Z. Simulation research of effects of different underlying surface types on outdoor thermal environment. J Tianjin Chengiian Univ. 2019;25:437-42.

36. McCullough EA, Jones BW, Zbikowski PJ. The effect of garment design on the thermal insulation values of clothing. ASHRAE Transactions. 1983:89:327-52.

37. Zhang W, Gao Z. Research progress of outdoor thermal comfort index. J Environ Health. 2015:32:836-40.

\section{Publisher's Note}

Springer Nature remains neutral with regard to jurisdictional claims in published maps and institutional affiliations.

\section{Submit your manuscript to a SpringerOpen ${ }^{\circ}$ journal and benefit from:}

- Convenient online submission

- Rigorous peer review

- Open access: articles freely available online

- High visibility within the field

- Retaining the copyright to your article

Submit your next manuscript at $\boldsymbol{\nabla}$ springeropen.com 